\title{
The Effect Of Food On The Pharmacokinetic
} Properties And Bioequivalence Of Two Formulations Of Levocetirizine Dihydrochloride In Healthy Chinese Volunteers

This article was published in the following Dove Press journal:

Drug Design, Development and Therapy

Yu Cheng,' Bi-Juan Lin,' Jin-Hua Guo,' Bing-Lin Huang,' Lin-Ping Fang,' Wan-Cai Que,' Mao-Bai Liu,' Xin-Feng Chen,' Hong-Qiang Qiu (iD) ${ }^{1,2}$

'Department of Pharmacy, Fujian Medical University Union Hospital, Fuzhou 35000I, People's Republic of China; ${ }^{2}$ College of Pharmacy, Fujian Medical University, Fuzhou 350004, People's Republic of China

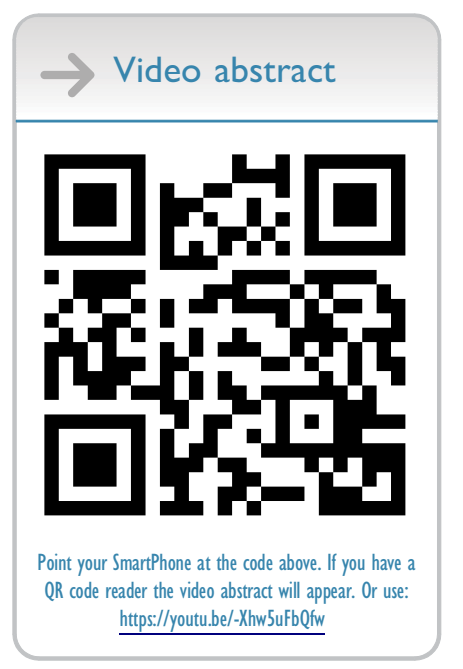

Correspondence: Hong-Qiang Qiu; Xin-Feng Chen

Department of Pharmacy, Fujian Medical University Union Hospital, 29 Xin Quan Road, Gulou, Fuzhou 35000I, Fujian, People's Republic of China

Tel +86 59l 862I 859I;

$+8659186218371$

Fax +86 591 8621 8591

Email hongqiangqiu@fjmu.edu.cn; fjxhcxf@163.com

\begin{abstract}
Purpose: The aim of this study is to assess the bioequivalence of a new generic formulation and the branded formulation of levocetirizine dihydrochloride in healthy Chinese volunteers under fasting and fed conditions, and food-intake effect on the pharmacokinetic properties is also evaluated.

Patients and methods: Volunteers were randomly allocated into two groups to receive a single oral dose of generic formulation and branded formulation under fasting or fed conditions, respectively. Blood samples were collected at designated time points. Plasma concentrations of levocetirizine were determined by UFLC-MS/MS. Safety evaluations were carried out through the study. The main pharmacokinetic parameters of the two formulations of levocetirizine were calculated using non-compartmental analysis incorporated in WinNonlin ${ }^{\circledR} 7.0$ software.

Results: Forty-nine volunteers were enrolled; 46 completed the studies. Under fasting and fed conditions, the $90 \%$ confidence intervals for the geometric mean of generic/branded ratios were in the range of $94.75-107.24 \%$ and $99.98-114.69 \%$ for the maximum observed concentration, and $97.13-102.50 \%$ and $98.36-103.98 \%$ for the area under the concentration-time curve. As a result of food intake before administration, the reduced rate and extent of absorption of levocetirizine were observed. Both formulations were generally well tolerated, with no serious adverse reactions reported.

Conclusion: The two formulations demonstrated essentially identical pharmacokinetic profiles and were all well within the FDA/CFDA bioequivalence standards. Meanwhile, food intake can delay the absorption rate and reduced the bioavailability of levocetirizine in healthy Chinese volunteers.
\end{abstract}

Keywords: levocetirizine, pharmacokinetics, bioequivalence, food effect, healthy Chinese volunteers

\section{Introduction}

Levocetirizine hydrochloride, the active $\mathrm{R}$ enantiomer of cetirizine hydrochloride, is a third-generation selective $\mathrm{H}_{1}$ receptor antagonist. The pharmacological effects of levocetirizine involve stabilizing the mast cell membrane, inhibiting early hypersensitivity reaction mediated by histamine, and depressing late anaphylaxis induced by eosinophils and basophils. ${ }^{1}$ It is widely used in the treatment of allergic diseases such as chronic urticaria, atopic dermatitis, allergic rhinitis, and allergic asthma. 
Levocetirizine is rapidly and extensively absorbed after oral administration. It is eliminated by renal excretion to a larger extent. ${ }^{2}$ The in vivo metabolic pathway for levocetirizine consists of oxidative hydroxylation, oxy-dealkylation, glucuronic acid-binding, and glutathione binding to sulfate formation. Unlike other $\mathrm{H}_{1}$ receptor blockers, levocetirizine cannot penetrate the blood-brain barrier, which contributes to the weak central inhibitory effect. Although levocetirizine is well tolerated, some adverse effects were reported in patients under therapy with levocetirizine. ${ }^{3-5}$ Most of the adverse effects of levocetirizine were dosedependent. For example, sedation was noted more significantly in the high-dose group. ${ }^{6}$ Inevitably, sometimes a higher dose of levocetirizine may be prescribed in the clinic. $^{7,8}$ Therefore, levocetirizine may not be an absolutely safe drug, especially for the patients who need a high dose or the patients with liver and kidney dysfunction. It is of great importance to ensure the quality of generic formulation that is comparable with the branded formulation.

Pharmacokinetic parameters: the maximal plasma concentration $\left(\mathrm{C}_{\max }\right)$, the time to peak plasma concentration $\left(\mathrm{T}_{\max }\right)$, and the area under the plasma concentration-time curve (AUC) are routinely used to evaluate the bioequivalence between two formulations. These parameters can be influenced by several factors, including gender, age, genetics, and ethnicity, as well as the drug quality and formulation, drug-drug and drug-food interactions. With regard to drug-food interactions, concomitant food intake may affect the pharmacokinetic process. Food exerts multiple effects on the absorption of many orally administrated drugs. ${ }^{9}$ It is worth noting that food can alter the bioavailability of orally administered drugs by various means, including delayed gastric emptying, stimulated bile flow, altered $\mathrm{pH}$ value in the gastrointestinal tract, increased splanchnic blood flow, changed in the luminal metabolism of a drug substance, and physical or chemical interaction with a dosage form or a drug substance. ${ }^{10}$ Food effects on bioavailability can have clinically significant consequences, leading to variations in efficacy and toxicity. Furthermore, a generic formulation that is bioequivalent compared with a branded formulation under fasting condition does not necessarily mean bioequivalent under fed condition. Due to the different preparation technique or application of excipients or interactions between excipients and the food-induced changes in gut physiology can contribute to these food effects and influence the bioequivalence. Currently, however, the detailed information describing the effects of food on the pharmacokinetic properties of levocetirizine has not been documented in any papers. It is important to clarify whether concomitantly administered food affects the pharmacokinetics of levocetirizine and evaluate the bioequivalence of drugs in both fasting and fed conditions.

Bioequivalence between generic and branded drugs is an issue that affects both clinical use and health care costs. ${ }^{11}$ Whether the generic and branded drugs are interchangeable, and whether their clinical efficacy is equal, can be the key concern of both clinicians and patients. However, due to the past defective policy of the China Food and Drug Administration (CFDA), most of the generic drugs are not really proven to be bioequivalent. In fact, there are many generic drugs with poor quality in the market, which lack sufficient therapeutic efficacy. Fortunately, in order to improve the quality of generic drugs, CFDA issued a deadline that all generic drugs administrated by oral route should pass bioequivalence evaluation no later than 2018. Now several versions of generic levocetirizine tablets are available in China, but few of them have proved to be bioequivalent through clinical study in healthy volunteers. Here is a generic drug, levocetirizine hydrochloride in the form of tablet, that has been developed by Suzhou Downray Pharmaceuticals. The current study aims to compare the bioequivalence of the new generic formulation with the branded drug levocetirizine hydrochloride $\left(\mathrm{Xyzal}^{\circledR}\right)$ in healthy Chinese volunteers, as well as the food-intake effect on the pharmacokinetics of levocetirizine.

\section{Materials And Methods Volunteers}

The study was aimed to enroll 48 healthy adult human volunteers (fasting: 24, fed: 24) according to the following criteria: (i) 18 65 years old (including 18 and 65 years) with a body mass index of $19.0 \sim 26.0 \mathrm{~kg} / \mathrm{m}^{2}$ (including 19.0 26.0); (ii) Volunteers were in good health condition that had no significant clinical symptoms or abnormal laboratory values. The volunteers were excluded based on the following criteria: (i) Volunteers with significant laboratory abnormalities or other significant disease histories should be excluded; (ii) Volunteers allergic to two or more drugs and food, or active ingredients and excipients; (iii) Volunteers on any other drugs (including Chinese herbs) within two weeks of the study; (iv) Volunteers positive with Nicotine or urine screening; (v) Volunteers 
that had a history of alcohol, drug abuse and addiction; (vi) Volunteers with birth plans (including male volunteers) during the study or within three months of the end of the study; (vii) Blood donation history within one month before the study; (viii) Volunteers that has been resumed by investigators with poor compliance or unsuitable to the study. All the volunteers underwent a complete physical examination.

\section{Study Design And Sample Collection}

The study protocol was approved by the ethics committee of Fujian Union Hospital (no.2017YW009), and all aspects of the study complied with the Declaration of Helsinki, Good Clinical Practice (GCP) guidelines, and the law and regulations of the People's Republic of China. Written informed consent was obtained from each volunteer.

A pilot study was performed before the formal study. A total of 8 healthy volunteers were involved in the pilot study (4 fastings and 4 feds). According to the results of the pilot bioequivalence study, a single-center, single-dose, open-label randomized two-arm self cross, and food effect study was designed to compare the bioequivalence of levocetirizine under fasting and fed conditions between the generic formulation (levocetirizine tablets, $5 \mathrm{mg}$, Suzhou Downray Pharmaceutical Co., Ltd., Lot No.: T150931001, purity: 98.5\%) and the branded formulation (levocetirizine tablets, $5 \mathrm{mg}$, UCB Farchim S.A., Lot No.: 192626, purity: 99.8\%). The random sequence was generated by gender using SAS 9.4. Eligible healthy volunteers who met the inclusion criteria obtained a unique volunteer number according to the succession of the enrollment, they were randomly assigned to either the generic-branded group or the branded-generic group by 1:1. The crossover part of the study was conducted after a 7-day wash-out period. The sample size of 24 volunteers in fasting or fed including $20 \%$ drop-outs would provide $80 \%$ power for AUC to ensure that the $90 \%$ confidence intervals (CIs) for the ratio of generic to branded according to Food and Drug Administration (FDA). ${ }^{12}$

In the fasting condition, after an overnight fast for at least $10 \mathrm{hrs}$, each volunteer received a single oral dose of 5 $\mathrm{mg}$ generic or branded formulation with about $240 \mathrm{~mL}$ of water according to the randomized scheme. Ethylenediaminetetraacetic acid-treated blood samples (3 $\mathrm{mL}$ ) were collected before drug administration and $0.17,0.33,0.5,0.75,1,1.25,1.5,2,2.5,3,4,6,8,12$, 24 and $36 \mathrm{hrs}$ after administration. Blood samples were centrifuged $\left(4^{\circ} \mathrm{C}, 3,000 \mathrm{rpm} \times 10 \mathrm{~min}\right)$ and stored at $-20^{\circ} \mathrm{C}$ before analysis.

In the fed condition, after an overnight fast for at least 10 hrs, each volunteer received a single oral $5 \mathrm{mg}$ dosage of the generic or the branded formulation with about $240 \mathrm{~mL}$ of water according to the randomized scheme after a standardized high-calorie and high-fat breakfast. The high-calorie and highfat breakfast (996.1 Kcal) provided in this study met the FDA guidelines, ${ }^{10}$ which contained $14.26 \%$ protein, $50.97 \%$ fat, and $34.77 \%$ carbohydrate $(250 \mathrm{~mL}$ of pure milk, $230 \mathrm{~g}$ of Caesar chicken roll manufactured by Starbucks ${ }^{\circledR}, 24 \mathrm{~g}$ of butter and 28 $\mathrm{g}$ of waffles). Ethylenediaminetetraacetic acid-treated blood samples $(3 \mathrm{~mL})$ were collected before drug administration and $0.25,0.5,0.75,1,1.25,1.5,1.75,2,2.5,3,3.5,4,6,8,12,24$ and $36 \mathrm{hrs}$ after administration. Blood samples were centrifuged $\left(4^{\circ} \mathrm{C}, 3,000 \mathrm{rpm} \times 10 \mathrm{~min}\right)$ and stored at $-20^{\circ} \mathrm{C}$ before analysis.

The volunteers were instructed to refrain from any intense activity or lying on the bed for a long time after the administration. Consumption of tea, coffee, and other beverages containing alcohol or coffee was restricted in the study, and smoking was also prohibited.

\section{Bioanalysis}

Levocetirizine concentrations in plasma were determined by using ultrafast liquid chromatography (Shimadzu ${ }^{\circledR}$ UFLC 20-AD)-tandem mass spectrometry (Sciex QTRAP $^{\circledR}$ 5500) (UFLC-MS/MS) method validated to FDA standards. ${ }^{13}$ After the sample was completely thawed, $50 \mu \mathrm{L}$ was added with levocetirizine- $\mathrm{d}^{4}(10 \mu \mathrm{L}$, internal standard, IS) and acetonitrile $(500 \mu \mathrm{L})$ in a 96well plate. The mixture was vortexed for $3 \mathrm{mins}$ and then was centrifuged at $4^{\circ} \mathrm{C}, 3,200 \mathrm{~g}$ for 5 mins. $200 \mu \mathrm{L}$ of the supernatant was evaporated at $40^{\circ} \mathrm{C}$ with nitrogen, and then the sample was reconstituted with the mobile phase. Finally, $2 \mu \mathrm{L}$ of the reconstitution was injected into the UFLC-MS/MS system for the analysis. Chromatographic separation was carried out at $40^{\circ} \mathrm{C}$ on Luna HILIC 200A column $(100 \times 2.0 \mathrm{~mm}, 5 \mu \mathrm{m})$ using an isocratic mobile phase system composed of acetonitrile and water $(0.4 \%$ formic acid, PH: 3.2) (5: 95, v/v) at a flow rate of $0.4 \mathrm{~mL} /$ min. The total run time was $3 \mathrm{~min}$. The detection of the analytes was performed in the positive ion and multiple reaction monitoring modes with transitions at $\mathrm{m} / \mathrm{z} 389.2$ 201.1 for levocetirizine, and at m/z 393.2-201.1 for IS.

There was no label for the generic and branded formulations in the collected plasma samples and only the period of fasting or fed was recorded on the label. This 
method ensured that the bioanalysis scientist kept the plasma samples as blind. After the analysis was completed, the result was given to the statistical analyst for bioequivalence analysis.

\section{Safety Evaluations}

Safety evaluations included adverse events (AEs), serious adverse events (SAEs), vital signs measurements (body temperature, heart rate, seated blood pressure, and respiration rate), physical examination data, laboratory tests (clinical chemistry, hematology, and coagulation tests), 12-lead electrocardiographs, and pregnancy test (female volunteers). Vital signs were assessed at $1 \mathrm{hrs}$ before and at 4, 12, 24, and $48 \mathrm{hrs}$ post-dose. The clinical staff closely monitored AEs throughout the study and graded the AEs as mild, moderate, or severe according to the definitions of "adverse drug reactions", "adverse events", and "severe adverse events" (ICH-E2A, Section II-B). If AEs occurred during the study, the volunteers were monitored until the end of AEs/until they are unwilling to continue the follow-up.

\section{Pharmacokinetic, Bioequivalence, And Statistical Analysis}

The main pharmacokinetic parameters of the two formulations of levocetirizine were calculated using non-compartmental analysis incorporated in WinNonlin ${ }^{\circledR} 7.0$ software. $C_{\max }$ and $\mathrm{T}_{\max }$ were calculated from the clinical trial data. The area under the plasma concentration-time curve $\left(\mathrm{AUC}_{0-36 \mathrm{~h}}\right)$ and the area under the plasma concentration-time curve extrapolated to infinity $\left(\mathrm{AUC}_{0-\infty}\right)$ were calculated using the trapezoid method. The elimination rate constant $\left(\lambda_{z}\right)$ was calculated from the least-squares regression slope of the terminal plasma concentration. Apparent elimination half-life $\left(\mathrm{t}_{1 / 2}\right)$ was calculated according to the formula $\left(t_{1 / 2}=0.693 / \lambda_{z}\right)$. $T_{\max }$ of the generic and the branded formulations was tested by the non-parametric test. The main pharmacokinetic parameters were transferred by natural logarithm and the significance test was performed by multivariate analysis of variance (ANOVA). If the geometric mean ratio of $90 \%$ confidence interval for the logtransformed $\mathrm{C}_{\max }$ and $\mathrm{AUC}$ is in the range of $80.00 \sim 125.00 \%$ (including boundary value), ${ }^{12,14}$ the generic formulation will assume to be equivalent to the branded formulation. ANOVA included four factors: individual, formulation factors, cycle, and sequence. Pharmacokinetic parameters, $\mathrm{AUC}_{0-36 \mathrm{~h}}$, $\mathrm{AUC}_{0-\infty}, \mathrm{t} 1 / 2, \mathrm{C}_{\max }$, and $\mathrm{T}_{\text {max }}$, for levocetirizine under fasting and fed conditions were analyzed by paired-samples $t$-tests.
Data were shown as mean \pm SD. $P<0.05$ was considered to be statistically significant.

\section{Results \\ Volunteers}

Fifty-four volunteers were screened in the fasting study and 24 volunteers (18 men and 6 women) enrolled. One volunteer was not treated in the second period and was withdrawn from the study due to sudden emergencies in the family, and one volunteer was discontinued due to illhealth during acupuncture before the administration and was not administered in both the periods. Fifty-four volunteers were screened in the fed study and 25 volunteers (19 men and 6 women) were enrolled in the fed study. One volunteer was withdrawn due to fever on the day of the admission and was not administered in two cycles and was replaced by another volunteer. Finally, a total of 46 volunteers (fasting: 22, fed: 24) completed a two-period crossover study (Figure 1). Baseline characteristics and demographics of volunteers included in the analysis are presented in Table 1. No significant differences in baseline characteristics and demographics of volunteers were found between each group in the study. None of the volunteers showed significant clinical conditions and the laboratory data showed no signs of hepatic or renal insufficiency.

\section{Bioanalysis}

The concentrations of levocetirizine in plasma were determined by the validated LC-MS/MS method. The assay was linear over the range of $1.00-400 \mathrm{ng} / \mathrm{mL}$ with the coefficients of variation for intra-day and inter-day less than $6.70 \%$ and relative error within $\pm 6.75 \%$. The lower limit of quantification of the method was $1.00 \mathrm{ng} / \mathrm{mL}$. In addition, 76 analyzed samples in the fasting study and 88 analyzed samples in the fed study were selected as incurred sample reanalysis (ISR). All plasma samples met the acceptance criteria. The pass ratio was $100 \%$.

It should be noted that all validation parameters (linearity, accuracy, precision, selectivity, sensitivity, matrix effect, extraction recovery, and stability) of this procedure met the criteria set out in the FDA guidelines. ${ }^{13}$

\section{Pharmacokinetic Analysis And Bioequivalence}

Mean plasma concentration-time profiles of levocetirizine after a single dose of the generic and branded formulations containing $5 \mathrm{mg}$ of levocetirizine for volunteers in fasting and 

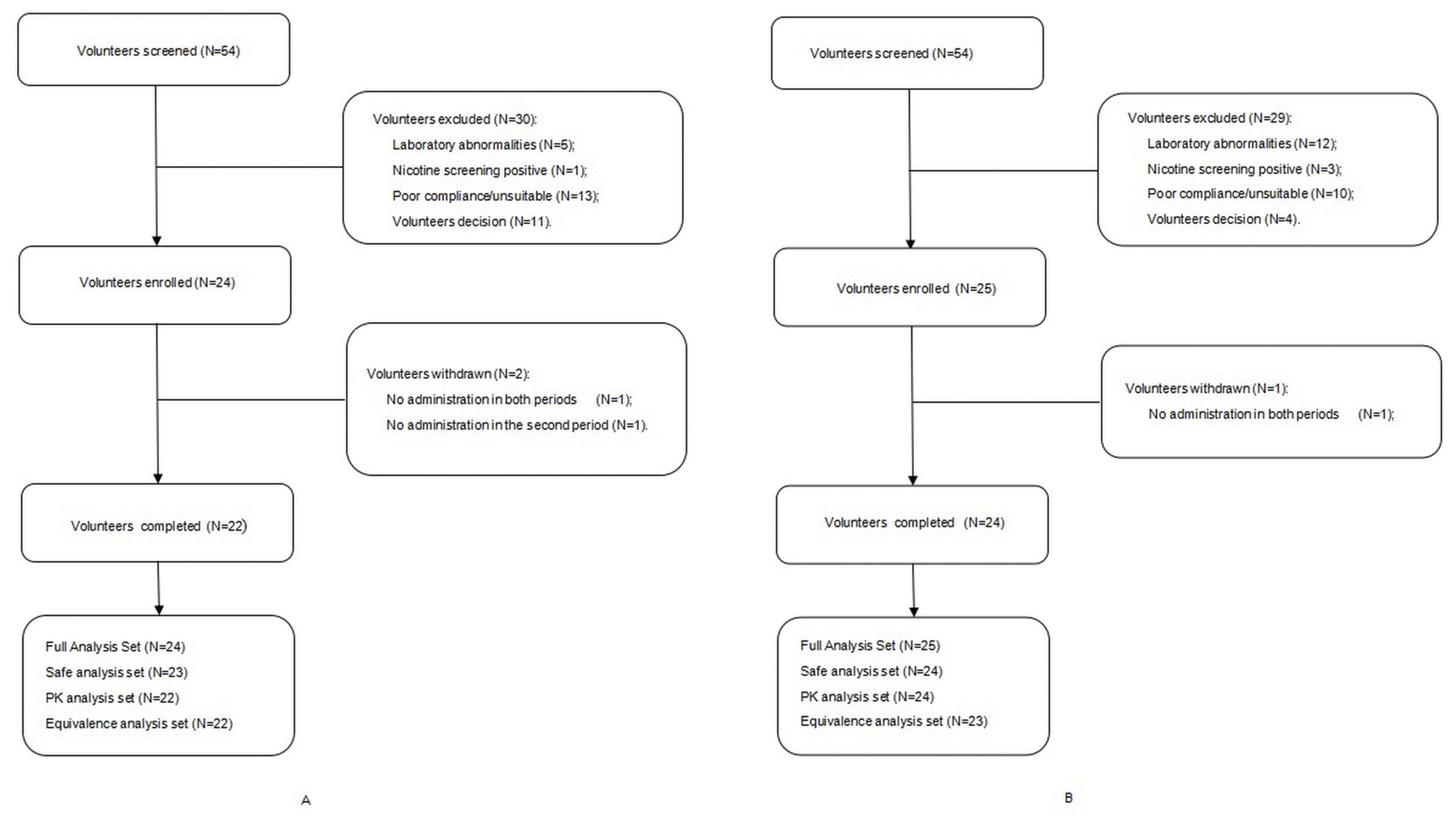

Figure I Study participation chart. (A) Fasting group; (B) Fed group.

fed states are shown in Figure 2. The main pharmacokinetic parameters are summarized in Table 2. Statistical analysis of pharmacokinetic parameters for volunteers in the fasting and fed studies are described in Tables 3 and 4. The results of the fasting study showed $90 \% \mathrm{CIs}$ for the geometric mean ratios of $\mathrm{C}_{\max }, \mathrm{AUC}_{0-36 \mathrm{~h}}$, and $\mathrm{AUC}_{0-\infty}$ were in the range of $94.75-$
$107.24 \%, 97.17-102.27 \%$, and $97.13-102.50 \%$. For the fed study, the first sampling point $(0.25 \mathrm{~h})$ of one volunteer was $\mathrm{C}_{\max }$. Therefore, the volunteer was excluded from the bioequivalence analysis. Finally, for the 23 volunteers in the fed condition, the $90 \%$ CIs for the geometric mean ratios of $\mathrm{C}_{\max }$, $\mathrm{AUC}_{0-36 \mathrm{~h}}$, and $\mathrm{AUC}_{0-\infty}$ were in the range of $99.98-114.69 \%$,

Table I Demographic Characteristics Of Volunteers In The Fasting And Fed Studies (Mean \pm SD [Range])

\begin{tabular}{|l|l|l|}
\hline Parameters & Fasting Study (n=24) & Fed Study (n=25) \\
\hline Sex, male/female & $18 / 6$ & $19 / 6$ \\
\hline Age, years, mean \pm SD [range] & $24.25 \pm 3.91[18-35]$ & $23.48 \pm 1.73[19-26]$ \\
\hline Weight, kg, mean \pm SD [range] & $62.40 \pm 6.40[52.1-76.5]$ & $62.34 \pm 8.01[49.9-83.6]$ \\
\hline Height, cm, mean \pm SD [range] & $169.92 \pm 5.93[160-179.5]$ & $170.42 \pm 6.77[161.5-189]$ \\
\hline BMI, kg/m², mean \pm SD [range] & $21.58 \pm 1.50[19.6-25]$ & $21.38 \pm 1.62[19.1-24.1]$ \\
\hline I2-lead electrocardiography, $n(\%)$ & & $17(68.0)$ \\
Normal & $22(91.67)$ & $8(32.0)$ \\
Abnormally, no clinical significance & $2(8.33)$ & 0 \\
Abnormally, the clinical significance & 0 & \\
\hline X-ray chest, $n$ (\%) & $21(87.5)$ & $25(100)$ \\
Normal & $3(12.5)$ & 0 \\
Abnormally, no clinical significance & 0 & 0 \\
Abnormally, the clinical significance & & \\
\hline
\end{tabular}

Abbreviation: BMI, body mass index. 


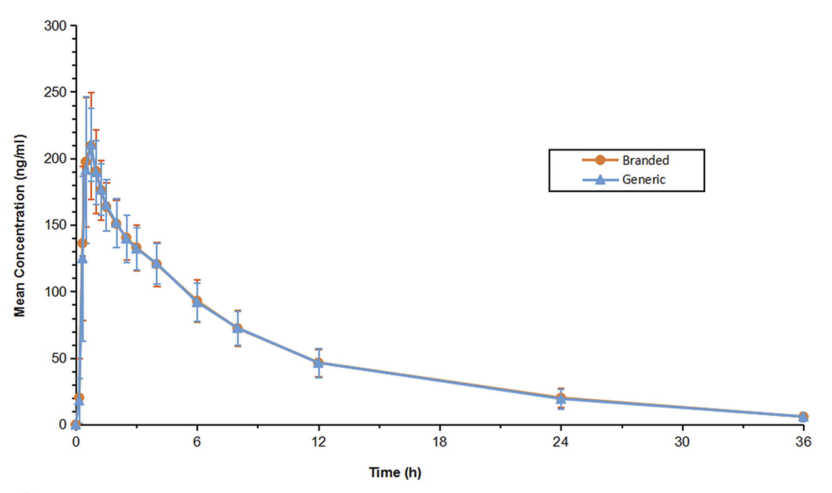

B

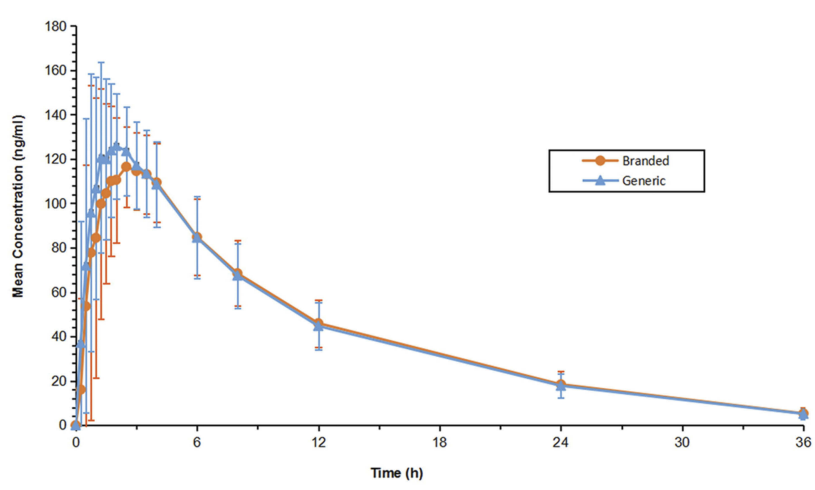

Figure 2 Mean $( \pm S D)$ plasma concentration-time profiles of levocetirizine after a single dose of the generic and branded formulations containing $5 \mathrm{mg}$ of levocetirizine for volunteers in (A) Fasting $(n=22)$ and $(B)$ Fed $(n=24)$ states.

98.71-103.96\%, and 98.36-103.98\%, respectively. The results of ANOVA showed that no significant difference existed in the pharmacokinetic parameters $\mathrm{C}_{\max }, \mathrm{AUC}_{0-\mathrm{t}}$, and $\mathrm{AUC}_{0-\infty}$ between the generic and branded formulations.

\section{Effect Of Food On Pharmacokinetics Of Levocetirizine}

The effect of food on the pharmacokinetics of levocetirizine was further explored. The mean plasma concentration-time profiles of levocetirizine in the fasting and fed states are shown in Figure 3. Compared with the fasting condition, the average values of $\mathrm{C}_{\max }$ and $\mathrm{AUC}$ for both generic and branded formulations under the fed condition were significantly reduced, and the average values of $\mathrm{T}_{\max }$ were nearly increased to 2-fold (Tables 2 and 3).

\section{Safety Evaluations}

Levocetirizine tablets $(5 \mathrm{mg}$ ) from the two different companies were well tolerated after administration of single oral dose under fasting and fed conditions in Chinese healthy volunteers. No serious AEs occurred in the study. A total of 47 volunteers entered the safety analysis set. Five cases of AEs occurred in 4 volunteers in the fasting study such as 1 case of elevated lactate dehydrogenase, 1 case of elevated body temperature, 1 case of nausea, 1 case of chest tightness, 1 case of herpes labialis. Four AEs occurred in 3 volunteers in the fed study: 1 case of elevated body temperature, 1 case of elevated lactate dehydrogenase, 1 case of heart rate reduction and 1 case of urinary tract infection. All AEs were mild in nature. Eight cases of AEs were found to be unrelated to the study drugs, and 1 case of AE (herpes labialis) was found to be very unlikely to the study drugs. All AEs were restored to normal at the end of the study.

\section{Discussion}

The present study set out with the aim of assessing the bioequivalence of the new generic formulation and the branded formulation in healthy Chinese volunteers, as well as the food-intake effect on the pharmacokinetics of levocetirizine. An open-label randomized single-dose study with double-cycle in a single center was designed. Before the formal study, a pilot study was performed to determine the individual difference of levocetirizine pharmacokinetics in Chinese volunteers, to evaluate the curve

Table 2 Main Pharmacokinetic Parameters For The Generic And Branded Formulations In Fasting And Fed Volunteers

\begin{tabular}{|c|c|c|c|c|}
\hline \multirow[t]{2}{*}{ Parameters } & \multicolumn{2}{|c|}{ Fasting Condition $(n=22)$ Arithmetic Mean \pm SD $(\% C V)$} & \multicolumn{2}{|c|}{ Fed Condition $(n=24)$ Arithmetic Mean $\pm S D(\% C V)$} \\
\hline & Generic Formulation & Branded Formulation & Generic Formulation & Branded Formulation \\
\hline${ }^{\mathrm{a}} \mathrm{T}_{\max }(\mathrm{h})$ & $0.75(0.33,1.25)$ & $0.75(0.33,1.50)$ & $1.38(0.25,3.50)^{* *}$ & $1.63(0.50,4.00)^{\# \#}$ \\
\hline $\mathrm{C}_{\max }(\mathrm{ng} / \mathrm{mL})$ & $219.23 \pm 29.05(13.25)$ & $219.09 \pm 36.78(16.79)$ & $154.13 \pm 20.89(13.56)^{* *}$ & $145.67 \pm 30.61(21.02)^{\# \#}$ \\
\hline $\mathrm{AUC}_{0-36 \mathrm{~h}}(\mathrm{~h} \cdot \mathrm{ng} / \mathrm{mL})$ & $1,737.88 \pm 290.85(16.74)$ & $1,750.33 \pm 3 \mid 5.88(\mid 8.05)$ & $1,501.58 \pm 263.24(17.53)^{*}$ & $1,482.16 \pm 265.66(17.92)^{\#}$ \\
\hline$A \cup C_{0-\infty}(h \cdot n g / m L)$ & $|, 808.7| \pm 337.99(\mid 8.69)$ & $1,819.22 \pm 358.46(19.70)$ & $1,559.76 \pm 287.15(|8.4|)^{*}$ & $1,542.97 \pm 294.92(19.11)^{\#}$ \\
\hline$\lambda z\left(h^{-1}\right)$ & $0.095 \pm 0.017(17.69)$ & $0.095 \pm 0.015(15.72)$ & $0.095 \pm 0.013(14.18)$ & $0.094 \pm 0.015(15.46)$ \\
\hline $\mathrm{tl} / 2(\mathrm{~h})$ & $7.50 \pm 1.37(18.19)$ & $7.48 \pm 1.20(15.98)$ & $7.47 \pm 1.01(13.57)$ & $7.50 \pm 1.11(14.82)$ \\
\hline
\end{tabular}

Notes: ${ }^{\mathrm{a}} \mathrm{Tmax}$ is expressed in median (minimum, maximum). $* \mathrm{P}<0.05, * * \mathrm{P}<0.01$ for the generic formulation of levocetirizine under fed condition versus that under fasting condition. ${ }^{\#} \mathrm{p}<0.05,{ }^{\#} \mathrm{p}<0.0 \mathrm{l}$ for the branded formulation of levocetirizine under fed condition versus that under fasting condition. 


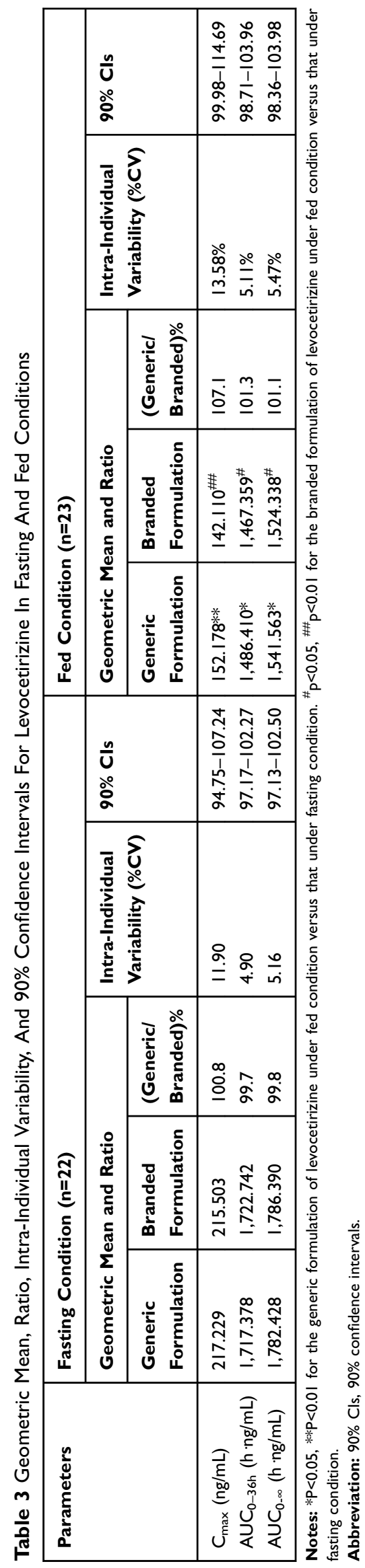

range for plasma sample analysis and to optimize the time point of blood sample collection. In the formal study, a total of 22 and 24 volunteers completed fasting and fed studies, respectively.

During sample analysis, quality control was carried out according to the relevant guidelines. The sample preparation was kept as quick and simple as possible. Compared with the chromatogram of the blank plasma sample, no interference of endogenous peaks was observed. The analytical range covered for each sample, and the accuracy for the intra-day/inter-day results was in the acceptable range. The results of all stability studies demonstrated the stability of levocetirizine across all determination steps. In addition, no apparent matrix effect was found to affect the determination of levocetirizine, including the normal, hyperlipemia, and hemolysis matrices. The difference between the concentrations measured by the ISR and the original samples met the requirement of $\pm 20 \%$ of the mean values.

Besides the formulation factor, bioequivalence may be affected by other confounders, such as study design, grouping, the period of time, and data processing method. Hence, the ANOVA analysis is employed. ANOVA of the log-transformed data indicated that formulation did not influence the outcome of all main pharmacokinetic parameters in this study. Individual differences are the main factors affecting pharmacokinetic parameters, which may be due to differences in metabolic levels or health status between individuals. According to the guidelines of FDA and CFDA, two different formulations can be considered to be bioequivalent if the $90 \%$ CIs of the geometric mean ratios of $\mathrm{C}_{\max }, \mathrm{AUC}_{0-\mathrm{t}}$, and $\mathrm{AUC}_{0-\infty}$ are contained within $80.0 \%$ to $125.0 \%$ interval, respectively. ${ }^{12,14}$ Our results met the regulatory requirements for bioequivalence, and the generic and branded formulations can be confirmed to be in the similar rate and extent of absorption, proving bioequivalence in two formulations under both fasting and fed conditions.

Pharmacokinetic parameters of levocetirizine measured under a fasting condition in the present study were in agreement with the previous studies. ${ }^{2,15}$ However, most of the published literature is focused on the bioequivalence of branded-to-generic or generic-to-generic substitutions under the fasting condition. There was little information on the effects of food on the bioequivalence and pharmacokinetic parameters of levocetirizine in Chinese. Only levocetirizine prescription information provided some description of the change of the pharmacokinetic 
Table $4 \mathrm{P}$ Values Of Multivariate Analysis Of The Generic And The Branded Formulations In Fasting And Fed Conditions

\begin{tabular}{|l|l|l|l|l|l|l|}
\hline \multirow{2}{*}{ Factors } & \multicolumn{2}{l|}{ Fasting Condition (n=22) } & \multicolumn{2}{l|}{ Fed Condition (n=23) } \\
\cline { 2 - 7 } & LnC $_{\max }$ & LnAUC $_{\mathbf{0 - t}}$ & LnAUC $_{\mathbf{0}-\infty}$ & LnC $_{\max }$ & LnAUC $_{\mathbf{0 - t}}$ & LnAUC $_{\mathbf{0}-\infty}$ \\
\hline Sequence & 0.533 & 0.927 & 0.870 & 0.634 & 0.653 & 0.654 \\
Cycle & 0.659 & 0.246 & 0.327 & 0.634 & $0.010^{* *}$ & $0.010^{* *}$ \\
Formulation factors & 0.826 & 0.836 & 0.888 & 0.101 & 0.402 & 0.494 \\
Individual & $0.023^{*}$ & $0.000^{* *}$ & $0.000^{* *}$ & $0.035^{*}$ & $0.000^{* *}$ & $0.000^{* *}$ \\
\hline
\end{tabular}

Notes: $* \mathrm{P}<0.05, * * \mathrm{P}<0.01$ for the generic formulation versus the branded formulation.

Abbreviations: $C_{\max }$, the maximal plasma concentration; $\mathrm{AUC}_{0-\mathrm{t}}$, the area under the plasma concentration-time curve; $A U C_{0-\infty}$, the area under the plasma concentrationtime curve extrapolated to infinity.

parameters after food intake. ${ }^{16}$ Consistent with the prescription information, our study found that $\mathrm{T}_{\max }$ was significantly delayed and $\mathrm{C}_{\max }$ was significantly decreased after administration with a high-fat meal for both the generic and branded formulations. However, our study failed to demonstrate that food had no effect on the extent of exposure (AUC) of the levocetirizine tablets, as per the prescription information. The present study revealed that the AUC of levocetirizine was significantly decreased under the fed condition for both the generic and branded formulations in the healthy Chinese population. Levocetirizine is orally administered into the gastrointestinal tract, and food in the gastrointestinal tract can affect all aspects of drug absorption, thereby affecting drug absorption and bioavailability. For example, the high-fat food may delay the rate of gastric emptying, change the $\mathrm{pH}$ of the gastrointestinal tract to affect the solubility of levocetirizine, or increase the viscosity of gastric juice to hinder the release and dissolution of levocetirizine on the surface of the gastric mucosa. ${ }^{9,17}$ An explanation, regarding the differences in the impact of food on drug exposure, may be of ethnic differences. Levocetirizine is a weak P-glycoprotein (P-gp) substrate, ${ }^{18}$ the polymorphism of

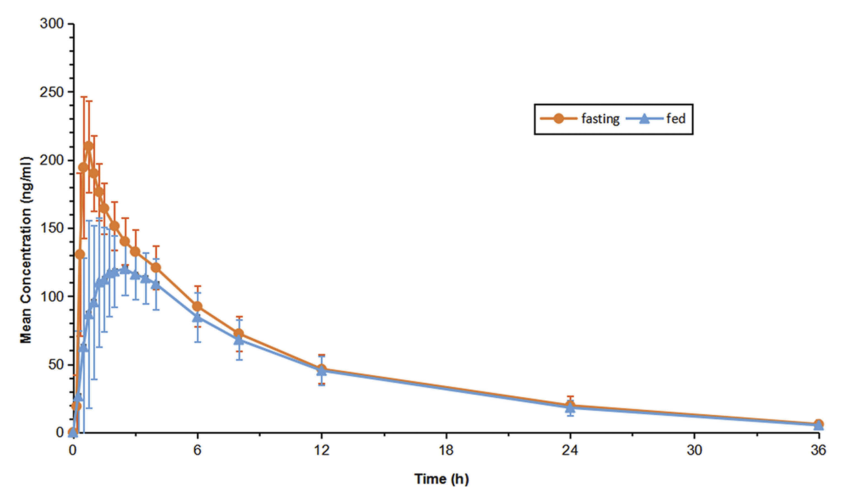

Figure 3 Mean $( \pm S D)$ plasma concentration-time profiles of levocetirizine in fasting $(n=22)$ and fed $(n=24)$ states.
P-gp gene $(A B C B 1)$ exhibited wide ethnic differences in the allele frequency. These nonsynonymous polymorphisms were considered to be clinically important because of their altered ATPase activity and substrate specificity toward different drugs. ${ }^{19}$ Meanwhile, P-glycoprotein (P-gp) gene could be a contributing factor and possibly a relevant marker for lipid disorder and obesity. ${ }^{20}$ Therefore, we speculated that there were differences in lipid metabolism between different races, which affected the food-drug interactions, resulting in a decrease in the bioavailability of levocetirizine in Chinese healthy volunteers under highfat food conditions compared with Western populations.

The safety results suggested both the generic and branded formulations were well tolerated by healthy volunteers under fasting and fed conditions, which was in line with previous research in adults, adolescents, and children with allergic conditions. ${ }^{21-23}$ There were no serious treatment-related, unexpected or unexplained AEs in either study. Combined with the results of food-intake effects, the high-fat food delayed the absorption rate and reduced the absorption amount of levocetirizine in healthy Chinese volunteers, and there was no difference of AEs between fasting and fed conditions. For antihistamine drugs, it was important to reach peak concentration quickly, ${ }^{24}$ so it was recommended to administer in the fasting condition.

\section{Conclusions}

The present study compared the bioequivalence of a generic formulation of levocetirizine with the originally branded tablet and also investigated the influence of food intake on the pharmacokinetics of levocetirizine. The two formulations demonstrated essentially identical pharmacokinetic profiles and were all well within the FDA/CFDA bioequivalence standards. Our results demonstrate that the newly developed generic formulation may provide a reliable alternative for patients with allergy. Meanwhile, food intake can delay the absorption rate and reduce the 
bioavailability of levocetirizine in healthy Chinese volunteers. Therefore, administration in the fasting state improves the bioavailability of levocetirizine in Chinese volunteers.

\section{Acknowledgments}

The authors thank all the volunteers who participated in this study. The authors also thank Priyanka Yeshwante from the University of North Carolina at Chapel Hill for professional language editing of the manuscript.

\section{Disclosure}

The authors report no conflicts of interest in this work.

\section{References}

1. Canonica G, Blaiss M. Antihistaminic, anti-inflammatory, and antiallergic properties of the nonsedating second-generation antihistamine desloratadine: a review of the evidence. World Allergy Organ J. 2011;4 (2):47-53. doi:10.1097/WOX.0b013e3182093e19

2. Benedetti M, Plisnier M, Kaise J, et al. Absorption, distribution, metabolism and excretion of [14C]levocetirizine, the $\mathrm{R}$ enantiomer of cetirizine, in healthy volunteers. Eur J Clin Pharmacol. 2001;57 (8):571-582. doi:10.1007/s002280100364

3. Layton D, Wilton L, Boshier A, Cornelius V, Harris S, Shakir SA. Comparison of the risk of drowsiness and sedation between levocetirizine and desloratadine: a prescription-event monitoring study in England. Drug Saf. 2006;29(10):897-909. doi:10.2165/00002018200629100-00007

4. Leynadier F, Mees K, Arendt C, Pinelli ME. Efficacy and safety of levocetirizine in seasonal allergic rhinitis. Acta Otorhinolaryngol Belg. 2001;55(4):305-312.

5. Snidvongs K, Seresirikachorn K, Khattiyawittayakun L, Chitsuthipakorn W. Sedative effects of levocetirizine: a systematic review and meta-analysis of randomized controlled studies. Drugs. 2017;77(2):175-186. doi:10.1007/s40265-016-0682-0

6. Sarkar T, Sil A, Pal S, Ghosh C, Das N. Effectiveness and safety of levocetirizine $10 \mathrm{mg}$ versus a combination of levocetirizine $5 \mathrm{mg}$ and montelukast $10 \mathrm{mg}$ in chronic urticaria resistant to levocetirizine $5 \mathrm{mg}$ : a double-blind, randomized, controlled trial. Indian J Dermatol Venereol Leprol. 2017;83(5):561-568. doi:10.4103/ijdvl.IJDVL_551_16

7. Bulca S, Bayramgurler D, Odyakmaz Demirsoy E, et al. Comparison of effects of 5 and $10 \mathrm{mg}$ oral desloratadine and levocetirizine on histamineinduced wheal and flare response in healthy volunteers. $J$ Dermatolog Treat. 2013;24(6):473-476. doi:10.3109/09546634.2013.777152

8. Tanizaki H, Nakamizo S, Nakahigashi K, Miyachi Y, Kabashima K. A double dose of levocetirizine leads to better control of histamineinduced flare, wheal and itch in healthy donors. Pharmacology. 2013;92(1-2):71-74. doi:10.1159/000353191

9. Abuhelwa A, Williams D, Upton R, Foster D. Food, gastrointestinal $\mathrm{pH}$, and models of oral drug absorption. Eur J Pharm Biopharm. 2017;112:234-248. doi:10.1016/j.ejpb.2016.11.034
10. U.S. Department of Health and Human Services, Food and Drug Administration, Center for Drug Evaluation and Research (CDER). Guidance for Industry: Food-Effect Bioavailability and Fed Bioequivalence Studies. 2017.

11. Shaw SJ, Hartman AL. The controversy over generic antiepileptic drugs. J Pediatr Pharmacol Ther. 2010;15(2):81-93.

12. U.S. Department of Health and Human Services, Food and Drug Administration, Center for Drug Evaluation and Research (CDER). Guidance for Industry: Bioequivalence Studies with Pharmacokinetic Endpoints for Drugs Submitted under an ANDA. 2013.

13. U.S. Department of Health and Human Services, Food and Drug Administration, Center for Drug Evaluation and Research (CDER), Center for Veterinary Medicine (CVM). Guidance for Industry: Bioanalytical Method Validation. 2017.

14. Center for Drug Evaluation, CFDA. Technical Guidelines for the Study of Bioequivalence of Chemical Drugs in Generic Drugs Using Pharmacokinetic Parameters as Endpoints. 2016.

15. Ino H, Hara K, Honma G, Doi Y, Fukase H. Comparison of levocetirizine pharmacokinetics after single doses of levocetirizine oral solution and cetirizine dry syrup in healthy Japanese male subjects. J Drug Assess. 2014;3(1):38-42. doi:10.3109/21556660.2014.928302

16. Xyzal. Product monograph. Available from: https://www.accessdata. fda.gov/drugsatfda_docs/label/2019/022064s038,022157s020lbl.pdf. Accesssed September 25, 2019.

17. Porter C, Mithani S, Dressman J, Charman W. Physicochemical and physiological mechanisms for the effects of food on drug absorption: the role of lipids and pH. J Pharm Sci. 1997;86(3):269-282. doi: $10.1021 /$ js $960085 \mathrm{v}$

18. Bartra J, Valero AL, del Cuvillo A, et al. Interactions of the $\mathrm{H}_{1}$ antihistamines. J Investig Allergol Clin Immunol. 2006;16(Suppl 1):S29S36.

19. Sakurai A, Onishi Y, Hirano H, et al. Quantitative structure-activity relationship analysis and molecular dynamics simulation to functionally validate nonsynonymous polymorphisms of human ABC transporter ABCB1 (P-glycoprotein/MDR1). Biochemistry. 2007;46 (26):7678-7693. doi:10.1021/bi700330b

20. Foucaud-Vignault M, Soayfane Z, Ménez C, et al. P-glycoprotein dysfunction contributes to hepatic steatosis and obesity in mice. PLoS One. 2011;6(9):e23614. doi:10.1371/journal.pone.0023614

21. Segall N, Gawchik S, Georges G, Haeusler JM. Efficacy and safety of levocetirizine in improving symptoms and health-related quality of life in US adults with seasonal allergic rhinitis: a randomized, placebo-controlled study. Ann Allergy Asthma Immunol. 2010;104 (3):259-267. doi:10.1016/j.anai.2009.12.003

22. Hampel F, Ratner P, Haeusler JM. Safety and tolerability of levocetirizine dihydrochloride in infants and children with allergic rhinitis or chronic urticaria. Allergy Asthma Proc. 2010;31(4):290-295. doi:10.2500/aap.2010.31.3349

23. Simons FE. Safety of levocetirizine treatment in young atopic children: an 18-month study. Pediatr Allergy Immunol. 2007;18(6):535542. doi:10.1111/pai.2007.18.issue-6

24. Pasko P, Rodacki T, Domagala-Rodacka R, Palimonka K, Marcinkowska M, Owczarek D. Second generation $\mathrm{H}_{1}$ - antihistamines interaction with food and alcohol-A systematic review. Biomed Pharmacother. 2017;93:27-39. doi:10.1016/j.biopha.2017.06.008 


\section{Publish your work in this journal}

Drug Design, Development and Therapy is an international, peerreviewed open-access journal that spans the spectrum of drug design and development through to clinical applications. Clinical outcomes, patient safety, and programs for the development and effective, safe, and sustained use of medicines are a feature of the journal, which has also

been accepted for indexing on PubMed Central. The manuscript management system is completely online and includes a very quick and fair peer-review system, which is all easy to use. Visit http://www. dovepress.com/testimonials.php to read real quotes from published authors. 